\title{
O DOBRO OU NADA: A REGULAÇÃO DE JOGOS DE AZAR
}

\author{
Carlos Emmanuel Joppert Ragazzo e Gustavo Sampaio de Abreu Ribeiro
}

DOUBLE OR NOTHING: GAMBLING GAMES REGULATION

\section{RESUMO}

ESTE ARTIGO DISCUTE A POSSÍVEL LEGALIZAC̣ÃO DE JOGOS DE AZAR NO BRASIL A PARTIR DE UMA ABORDAGEM RACIONAL SOBRE OS OBJETIVOS REGULATÓRIOS A SEREM PERSEGUIDOS. INICIALMENTE SÃO ANALISADOS OS PRINCIPAIS ARGUMENTOS UTILIZADOS PARA LEGALIZAR OS JOGOS NO BRASIL. A SEGUIR, OS AUTORES IDENTIFICAM E ELABORAM OS POTENCIAIS CUSTOS E BENEFÍCIOS ASSOCIADOS PELA LITERATURA A DETERMINADOS TIPOS DE JOGOS. POR FIM, TAMBÉM SERÃO APRESENTADOS E DISCUTIDOS ELEMENTOS ATUALMENTE FORA DO, OU MARGINAIS AO DEBATE, OS QUAIS OS AUTORES CONSIDERAM PARA SE PENSAR EM DIFERENTES LINHAS DE AÇÃO PARA REGULAR JOGOS DE AZAR, E UMA ANÁLISE MAIS PORMENORIZADA DE VARIÁVEIS IMPORTANTES PARA A REGULAÇ̃̃O DO SETOR. A PROPOSTA DESTE ARTIGO É APONTAR UM DIRECIONAMENTO PARA O DEBATE SOBRE JOGOS DE AZAR NO BRASIL DE FORMA A TORNÁ-LOS VIÁVEIS.

\section{PALAVRAS-CHAVE}

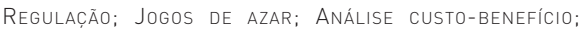
JOGADORES PATOLÓgICOS; ALTERNATIVAS REgULATÓRIAS.

\section{ABSTRACT}

THIS ARTICLE DISCUSSES THE POSSIBLE LEGALIZATION OF GAMBLING IN BRAZIL FROM A RATIONAL APPROACH ON REGULATORY OBJECTIVES TO BE PURSUED. FIRST, THE MAIN ARGUMENTS THAT ARE USED FOR LEGALIZING THE GAMES IN BRAZIL ARE ANALYZED. NEXT, THE AUTHORS IDENTIFY AND ESTABLISH THE POTENTIAL COSTS AND BENEFITS THAT SPECIALIZED LITERATURE ASSOCIATES WITH CERTAIN TYPES OF GAMES. VARIABLES AND ELEMENTS CURRENTLY ON THE OUTSKIRTS OF DEBATE AND THAT THE AUTHORS CONSIDER IMPORTANT FOR THE REFLECTION OF DIFFERENT LINES OF ACTION TO REGULATE GAMBLING WILL BE DISCUSSED. ALSO, THIS ARTICLE WILL BRING FORWARD A MORE DETAILED ANALYSIS OF IMPORTANT VARIABLES FOR SECTOR. THE AIM OF THIS PAPER IS TO POINT THE DEBATE ON GAMBLING IN BRAZIL TOWARDS A DIRECTION THAT WILL MAKE THIS ECONOMIC ACTIVITY VIABLE.

\section{KEYWORDS}

REGULATION; GAMBLING GAMES; COST-BENEFIT ANALYSIS; PATHOLOGICAL GAMBLERS; REGULATORY ALTERNATIVES

\section{INTRODUÇÃO}

"Só mais uma aposta”, implora o jogador. "Desta vez vai." Uma nova aposta é feita. Já foram várias. Dezenas. O salário do mês foi gasto há tempo. As dívidas crescem. O coração acelera. A ansiedade aumenta. Ele perde. "De novo!" Essa descrição parece tirada de um cassino ou de uma casa de jogo do bicho. Certo? Errado. Trata-se de uma cena em uma casa lotérica. O jogo: mega-sena. O jogador: qualquer brasileiro. 
A atual discussão sobre regulação de jogos de azar no Brasil está viciada. Viciada não em dados ou roletas, mas em preconceitos, argumentos falaciosos e perguntas que erram o foco da discussão. O objetivo deste artigo é reformular o debate. A questão não é se devemos trazer para a legalidade diferentes indústrias de jogos hoje ilegais, ou quanto de receita tributária a regularização de jogos trará. As questões que propomos debater são: as pessoas devem ou não ter acesso a jogos? Essa é uma prática que queremos estimular ou desestimular? O desafio é que essas perguntas não são tão simples quando formuladas da seguinte forma: Quais são os tipos de jogos que queremos (des) estimular para quais pessoas, sob quais condições?

Essa questão é eminentemente política e refere-se a que tipo de sociedade queremos viver e estruturar. Contudo, argumentos racionais podem ser trazidos à mesa para que possamos tentar organizar um debate democrático minimamente controlável sobre os objetivos regulatórios e, a partir daí, talharmos artesanalmente a medida regulatória mais apta a atingi-los, e menos custosa. Para essa discussão racional é indispensável empregar uma metodologia de avaliação que nos permita comparar custos e benefícios de possíveis propostas, ao mesmo tempo em que torne explícitas as premissas dos argumentos levantados.

O obstáculo inicial é a superação do conjunto de argumentos recorrentes, em grande parte falaciosos, que pautam o atual debate sobre a matéria, quais sejam: o binômio "legalização/arrecadação"; o argumento do desenvolvimento econômico, principalmente para fomentar o turismo; e o reconhecimento de aceitação do jogo no cotidiano.

Este artigo está divido em quatro sessões, além desta Introdução. Na primeira, analisamos os principais argumentos utilizados para legalizar os jogos no Brasil. Na segunda, identificamos e elaboramos os potenciais custos e benefícios associados pela literatura a determinados tipos de jogos. Em particular, destacamos exemplos de custos nas categorias: crimes; doenças; falência pessoal; e aspectos produtivos. Dentre os benefícios, elaboramos sobre estas categorias: economia; crimes; e utilidade. Tudo isso é necessário para ajustar as perguntas ao debate.

Na terceira sessão, apresentamos e discutimos os elementos atualmente fora do, ou marginais ao debate, os quais entendemos ser altamente relevantes para se pensar em diferentes linhas de ação a fim de regular os jogos de azar, quais sejam: tipos de jogos e tipos de jogadores. Ao colocar tais elementos no centro do debate esperamos trazer à mesa perguntas que possam reformular o debate e pautar novas propostas legislativas.

Na última sessão focamos nossa discussão em uma análise mais pormenorizada de variáveis importantes para a regulação do setor, a saber: entrada, qualidade e informação - sendo as duas últimas de regulação prudencial. Cada variável impõe um tipo diferente de racionalidade e custo, pois significam, entre outras coisas, aparatos regulatórios diferentes, bem como incentivos e consequências diversas para os 
atores econômicos. $\mathrm{O}$ artigo termina com uma Conclusão, na qual apontamos uma direção para o debate sobre jogos de azar no Brasil, de forma a torná-los viáveis.

Os dados estão lançados. Façam suas apostas.

\section{Propostas na mesa: argumentos frequentemente utilizados}

\section{I BinôMIO “LEGALIZAÇÃo/ARRECADAÇÃo”}

Por binômio "legalização/arrecadação" queremos dizer o argumento, usualmente levantado no atual debate sobre regulamentação de jogos de azar, fundamentado em dois pilares. O primeiro é a presunção de que, se legalizarmos a prática de determinado jogo de azar, estaremos contribuindo para a retirada da ilegalidade de uma indústria que resiste à (suposta) repressão estatal. O segundo pilar é que, uma vez legalizados os jogos, essa indústria passará a pagar tributos, aumentando a receita tributária dos entes federativos competentes. O nosso argumento é que o binômio "legalização/arrecadação” pauta grande parte do atual debate sobre regulação de jogos de azar. ${ }^{1}$

O problema desse binômio é que ele está baseado em duas premissas: uma falsa e outra problemática. Primeiro, a premissa falsa. Não é necessariamente lógico que a simples regulamentação de um determinado jogo de azar, atualmente proibido, fará com que essa indústria, hoje ilegal, seja regularizada. Qualquer que seja o nível de permissão (mais ou menos restritivo) de uma determinada atividade, sempre haverá um contingente de atores que se manterão na ilegalidade. Isso se deve a vários fatores, por exemplo, o alto grau de regulação e tributos levam muitos agentes a se manter na ilegalidade para fugir de alguns tipos de custos associados à regularização e à manutenção desse status. ${ }^{2}$

Além disso, os jogos de azar, permanecendo ilegais, proporcionam aos usuários o que se pode denominar de "fator adrenalina" extra. Isto se refere ao ganho marginal de utilidade que o indivíduo percebe ao participar de jogos ilegais pelo simples fato de serem ilegais. Dado que o "fator adrenalina" é perdido quando determinada forma de jogo de azar é legalizada, os usuários que procuram essa adrenalina transferirão seus recursos para outras formas de jogos ilegais. Isso mantém a demanda dessa indústria. A regulamentação do jogo do bicho, portanto, não importará na legalização de todos aqueles que o exploram. Ao regulamentar a prática de determinado jogo de azar (como o jogo do bicho), não estaremos trazendo para a legalidade toda a indústria atualmente ilegal, mas sim incentivando a criação de uma nova indústria, ou ao menos a expansão de uma já existente. Ou seja, o resultado não seria trazer para a legalidade o existente, e sim incentivar a criação do novo (legal), mas mantendo-se o ilegal, ainda que em menor medida (KINDT, 1994).

Segundo, a premissa problemática. Esta se refere ao argumento de que o aumento na receita estatal, decorrente da tributação da nova indústria, agora legalizada, 
traria um ganho líquido para o orçamento público, o que possibilitaria novos investimentos em diversas causas "nobres" (e.g. saúde, educação, cultura, esportes, etc.). Esse tipo de raciocínio possui alguns problemas. Devemos considerar que parte dos recursos adicionais arrecadados pelo governo pode vir a ser mais do que compensado por eventuais incrementos na despesa em outras áreas decorrentes da verificação dos custos potenciais associados à prática de jogos. Essas áreas incluem segurança, fiscalização e saúde pública, dentre outras, dependendo de quais modalidades de jogos serão regularizadas e como isso será feito. Não é perfeitamente claro se o impacto final no orçamento público vai ser positivo.

\section{I.2 Desenvolvimento eCONÔMico E Turístico}

Outro exemplo de argumento, rotineiramente encontrado nas justificativas anexadas aos projetos de lei atualmente em discussão no Congresso Nacional, é que a regularização de jogos de azar pode contribuir para o desenvolvimento econômico de uma determinada região, em especial ao fomentar o turismo naquela área. ${ }^{3}$ Argumenta-se que a legalização de jogos proporciona ganhos econômicos para a comunidade. Isso ocorreria, por exemplo, por meio do aumento da oferta de empregos. ${ }^{4}$ Em particular, diferentemente de outras indústrias, a exploração de jogos tenderia a criar grande quantidade de empregos de tempo integral e de baixa qualificação, necessários em comunidades que sofrem com o desemprego crônico. ${ }^{5}$ Melhorias em infraestrutura, em particular nos transportes, também são usualmente associadas a essa indústria.

Contudo, uma eventual contribuição para o desenvolvimento econômico de áreas (e.g. pela melhoria da infraestrutura local, valorização dos imóveis) não deve ser computada como benefício líquido claro e inequívoco. As estatísticas não são incontroversas ao avaliar se esse tipo de desenvolvimento econômico em uma região aconteceria realmente (NGISC, 1999). Grande parte das melhorias em infraestrutura é financiada por meio do orçamento público, logo, não poderia ser creditada somente ao setor regulado, ainda que este pudesse gerar a demanda e a pressão política. Mesmo que o financiamento público viesse de receitas adicionais conseguidas com a legalização de jogos, haveria ainda "o custo" de oportunidade de se investir esses recursos em outros fins.

Temos que chamar a atenção, também, para o reconhecimento de que aquilo que muitos chamam de "indústria de jogos" na realidade envolve segmentos muito diferentes entre si. ${ }^{6}$ Ainda que muitos de nós, ao se falar em jogos, pensemos imediatamente em cassino, este não é o único tipo de ofertante. Na realidade, as formas de jogos que tendem a ser mais habituais são loterias, mas há outras que comumente são disponibilizadas em pequenos estabelecimentos (e.g. raspadinha, slot machines, etc.). Estas possuem benefícios mais negligenciáveis e são mais problemáticas em vários aspectos, como a probabilidade de abuso e a contribuição para o desenvolvimento e agravamento de patologias. 
O argumento em prol do fomento da indústria do turismo em função da regularização de jogos é mais complexo do que pode parecer inicialmente. Por trás do fomento do turismo como política de desenvolvimento está a noção de que o turismo criaria uma demanda "externa" em determinada comunidade. É como se o mercado consumidor daquela localidade fosse aumentado sem o correlato aumento de sua população residente. Isto é diferente de uma "transferência" de demanda de determinados produtos ou serviços para outros, o que ocorre quando um consumidor migra de um produto ou serviço para outro substituto, por exemplo.

O fluxo de riqueza que deriva de atividades de turismo, sem dúvida, pode ser encarado como benefício que advém normalmente do jogo. No entanto, há que se levantar um argumento relacionado ao custo de oportunidade de onde se libera o jogo. A criação de uma indústria de jogos pode ser uma solução potencialmente interessante para áreas isoladas e pouco atrativas para o turismo em geral, a exemplo do Recôncavo Baiano. Contudo, isso pode não ser verdadeiro para regiões como Rio de Janeiro e São Paulo, que já contam com um elevado número de atrações turísticas e de turistas.

\section{3 Aceitação pelo Cotidiano}

Outro argumento rotineiramente trazido para justificar diversos dos atuais projetos de lei em favor da legalização de determinado jogo de azar é a "aceitação pelo cotidiano”. O raciocínio é o seguinte: dado que grande parte da população convive de forma harmoniosa com a presença disseminada de vários tipos de jogos de azar, estes devem ser legalizados. ${ }^{7}$

O que significa ser “aceito” por qual "parcela” da população? Algo que é "aceito” por grande parte da população talvez não deva ser tolerado ou legalizado. Durante muito tempo, a escravidão foi "aceita" pela aristocracia branca. Durante muitos anos, diversas formas de repressão explícita às mulheres eram aceitas pela elite masculina e, em certo sentido, "toleradas" pelas próprias mulheres, como a falta de direito ao voto e a restrição no ingresso em escolas e universidades. Atualmente, grande parte da sociedade não aceitaria esses fatos como argumentos em prol da manutenção daquele statu quo.

A discussão sobre a regulamentação dos jogos não deve ser pautada pela tolerância da prática por determinada parcela da sociedade em determinado momento histórico, e sim por uma criteriosa análise dos custos e benefícios da prática em questão.

\section{I.4 REDEFININDO O FOCO DO DEBATE: QUAIS SÃO AS PERGUNTAS CORRETAS?}

Questões como deve-se legalizar ou não os jogos e como estes devem ser regulados esbarram necessariamente nesta questão: queremos estimular ou desestimular essa prática? Atividades que acreditamos gerar impactos negativos, que superem os possíveis benefícios (se houver), tendem a ser desestimuladas por meio de proibição. Isso se aplica a qualquer atividade que gere risco: uso de drogas pesadas, como heroína, cocaína e 
crack. Algumas atividades, que optamos proibir, visam o desestímulo do consumo, pois acredita-se que elas geram mais resultados nocivos do que benefícios.

Todo debate a respeito da liberação dos jogos está focado em perguntas erradas. A receita decorrente de turismo e do aumento de arrecadação de tributos, ou mesmo a suposta ampla aceitação de jogos de azar pela sociedade, não representam as grandes questões a serem avaliadas na decisão política de legalizá-los. As perguntas são outras. As pessoas devem ter acesso a jogos? Essa é uma prática que queremos estimular ou desestimular? Estas, sim, são perguntas que deveriam figurar no centro do debate. E a resposta precisa ter por base uma metodologia de análise que permita tornar explícitas as premissas de cada argumento, e possibilite uma comparação mais transparente e criteriosa dos custos e dos benefícios envolvidos em cada alternativa. É o que abordaremos na próxima sessão.

\section{AnÁlise CuSTO-BENEFício}

Atualmente não há uma metodologia bem definida na tradição jurídica brasileira para determinar o processo de escolha da solução regulatória a ser implementada (RAGAZZO, 2011a). Isso abre espaço para a implementação de uma cultura regulatória que leve a sério uma devida e criteriosa análise dos potenciais custos e benefícios associados a cada possível linha regulatória, para avaliar cada alternativa antes de se chegar a uma conclusão. A mudança do paradigma regulatório em prol da realização sistemática de análises de custos e benefícios de cada proposta engendraria um salto de qualidade no processo decisório na administração pública. Isto porque contribuiria, entre outras coisas, para evitar os riscos de decisões arbitrárias, e a ocorrência de efeitos não previstos ou a prevalência de interesses de grupos políticos específicos, a despeito da transparência, da inclusão de debates e da fundamentação das decisões administrativas (RAGAZZO, 2011a).

Nas próximas sessões trataremos de exemplos de custos e de benefícios normalmente associados à indústria de jogos de azar. Não temos a pretensão de exaurir a lista, e sim identificar e discutir alguns dos principais itens. A esperança é que esse exercício nos ajude a reformular o debate sobre regulação de jogos de azar no Brasil, expondo um amplo conjunto de argumentos, atualmente ausentes ou marginais, nas discussões.

É importante destacar que estamos mais preocupados em identificar e discutir potenciais custos sociais do que quantificá-los. Problemas como a coleta de dados e a escolha da metodologia adequada dificultam a mensuração de custos e benefícios. Esses desafios podem explicar, em parte, a relativa escassez de análises quantitativas na literatura. ${ }^{8}$

\section{I Custos}

O tema "custos sociais associados a jogos de azar" é bastante controverso na literatura 
econômica especializada. Alguns autores argumentam que muitas pesquisas que procuram elencar e medir os custos sociais associados a jogos de azar fazem uso equivocado do conceito econômico de custo social, além de apresentarem problemas metodológicos graves (WALKER, 2008 e WALKER e BERNETT, 1999). Esses autores argumentam que custos ditos "sociais", na realidade, são exemplos de transferências de renda ou são exemplos de externalidades que acabam sendo internalizadas por algum ator econômico. Portanto, não constituiriam verdadeiros custos sociais, que estariam presentes apenas quando se verifica uma efetiva diminuição na riqueza total da sociedade.

Neste texto, procuramos fugir dessa discussão e adotamos uma concepção ampla de "custo social”, abrangendo exemplos além da definição clássica de livros e textos de economia do bem-estar social. Não ficamos restritos apenas a custos meramente "sociais", ou seja, custos arcados apenas pela sociedade em sentido amplo. As consequências negativas dos jogos de azar suportadas pelo próprio indivíduo e/ou pela família deste, pelo empregador, etc., também devem compor o leque de custos associados à atividade. Assim, não excluímos ex hypothesi os custos internalizados, mas guardamos em mente que as consequências negativas podem não reduzir a riqueza total da sociedade.

Da mesma forma procuramos destacar, quando era relevante, a existência de consequências caracterizadas como "meras" transferências econômicas. A justificativa para isso é que, ainda que estejamos preocupados com perdas efetivas de riqueza, isso não invalida, muito menos impossibilita, uma preocupação com certos tipos de transferências. Dependendo dos nossos objetivos políticos, podemos considerar determinadas transferências como não desejáveis.

Dito isso, podemos categorizar os custos associados a jogos que identificaremos e discutiremos em quatro grupos: crimes, doenças, falência pessoal e aspectos produtivos. Alguns exemplos de custos discutidos reverberam em mais de uma categoria. Lembramos que não tivemos a pretensão de criar uma lista exaustiva; a divisão, no entanto, auxiliará em termos didáticos e também a avaliar como cada tipo de custo pode ser agravado ou atenuado em função do tipo de jogo ou do tipo de usuário, e pensar a respeito de medidas regulatórias específicas e mais eficazes.

A primeira categoria de custos se refere ao impacto de jogos na criminalidade. A premissa subjacente é que alguns tipos de jogos aumentam a criminalidade de uma determinada região, e isso pode ocorrer indireta e diretamente (GRINOLS e MUSTARD, 2006). Indiretamente, por reduzir o desenvolvimento econômico de uma área (repare como aqui a premissa quanto ao impacto de jogos no desenvolvimento econômico muda), alguns tipos de jogos de azar podem atrair atividades como exploração de prostituição, tráfico de drogas, contrabando e corrupção de oficiais públicos, além de outras relacionadas a maiores taxas de violência (furtos, homicídios e outros crimes). ${ }^{9}$ Diretamente, porque alguns tipos de jogos podem diminuir os custos de informação e aumentar os ganhos de atividades ilegais. Por exemplo, turistas são normalmente mais 
vulneráveis a certos tipos de crimes, como roubo e furto. Presumindo que os jogos tendem a atrair turistas, haveria um acréscimo no payoff desses crimes pela maior concentração de vítimas com esse perfil. Além disso, os cassinos são historicamente locais de lavagem de dinheiro proveniente de atividades ilegais, como o tráfico de drogas. Assim, a existência desses estabelecimentos tornaria essa prática mais vantajosa, com todas suas externalidades negativas consequentes.

A taxa de criminalidade também pode aumentar em função do aumento de jogadores patológicos. ${ }^{10}$ À medida que os recursos e o acesso alternativo a fontes de renda vão se tornando escassos, os jogadores patológicos tendem a recorrer ao cometimento de crimes contra a propriedade (e.g. furtos, roubos e fraudes) para jogar ou pagar suas dívidas de jogo, bem como para manter as aparências.

O aumento na criminalidade gera efetivamente custos dos mais diversos. Destacaremos os mais evidentes. Há os custos administrativos não triviais, como a manutenção (ou aumento) do sistema de repressão policial, do sistema judicial penal, de prisões e outras penas restritivas de direitos e liberdade, etc. Nessa mesma categoria estão incluídos custos privados com segurança (câmeras, muros, alarmes), que canalizam recursos que poderiam ser investidos em outras iniciativas mais produtivas. Podemos citar também a possível não realização de investimentos por insegurança. Esse cenário geraria um aumento nos preços das apólices de seguro, o que novamente desviaria recursos sociais de setores mais produtivos. Logicamente, o que se refere aqui é o acréscimo marginal desses custos, que já existem por outras razões decorrentes de atividades relacionadas aos jogos de azar.

A segunda categoria de custo usualmente associada a jogos de azar se refere às doenças que advêm dessa prática. Os exemplos mais comuns são casos de depressão, distúrbios de déficit de atenção e hiperatividade, e distúrbios de personalidade, além de outros quadros clínicos causados por estresse. Tudo isso tende a aumentar as tentativas de suicídio, divórcios, violência doméstica, abuso de crianças, entre outros efeitos deletérios à sociedade. ${ }^{11}$ Além disso, aumentam os custos com tratamentos de saúde, com médicos, medicamentos, equipamentos hospitalares, etc. que acarretam a perda do bem-estar. ${ }^{12}$

De grande relevância é a constatação de que a legalização de jogos aumenta o problema do jogo patológico. Esse aumento pode se dar, por exemplo, pelo fato de que a expansão geográfica de cassinos diminui o custo de compra do produto objeto do vício, o que tende a aumentar a "quantidade consumida" por jogadores compulsivos. Esse argumento é suportado por algumas constatações, como o aumento significativo dos encontros de jogadores anônimos após a abertura de cassinos em determinadas localidades, ${ }^{13}$ e a diminuição de ligações para grupos de ajuda, quando houve uma redução nas oportunidades disponíveis de jogo (e.g. banimento de slot machines) em certas cidades. ${ }^{14}$ Esse tema será tratado mais em detalhe, quando discutirmos os desafios regulatórios específicos que jogadores patológicos impõem. 
A terceira categoria importante de consequências negativas associadas a jogos de azar diz respeito ao aumento do endividamento e o consequente aumento dos casos de falência pessoal de uma parcela de jogadores, pois os indivíduos tenderiam a colocar em risco uma elevada parcela de seu patrimônio e, consequentemente, correriam riscos de ficar inadimplentes.

Além disso, do ponto de vista do nível de riqueza total da sociedade, apenas a porção do nível de endividamento adicional que não é paga deve ser considerada custo efetivo para a sociedade (NGISC, 1999). Ainda assim, esse montante não pode ser atribuído indiscriminadamente a jogos. É possível que os jogadores patológicos inadimplissem suas dívidas ainda que não tivessem a patologia. $\mathrm{O}$ aumento no nível de endividamento inclui os custos sociais relacionados, dentre outros, a atos de cobranças como avisos extrajudiciais e processos cíveis. Apontamos, também, uma série de externalidades negativas, como um possível aumento no custo do crédito em geral e, em maior nível, para clientes com histórico de jogo patológico.

Outro aspecto interessante quanto à possibilidade de falência pessoal em função de jogo é o argumento de que o vício é mais custoso na medida em que é mais difícil para o indivíduo declarar falência pessoal e gozar da consequente liberação de suas dívidas. Esse argumento se baseia na existência, em alguns sistemas jurídicos, do instituto da falência pessoal, por meio do qual pessoas naturais, em determinadas condições e preenchidos certos requisitos, podem requerer falência e, assim, serem capazes de extinguir ou renegociar suas dívidas, incluindo as de jogos.

A ideia aqui é baseada em incentivos. Uma vez que o indivíduo pode requerer facilmente falência e extinguir ou renegociar suas dívidas de jogo, ele encararia a situação de falência pessoal como menos custosa. Como, para esse mesmo individuo, os custos de perder tudo são menores, ele estaria mais disposto a apostar repetidamente uma parcela cada vez maior de seu patrimônio. A manutenção dessa situação pode contribuir para o aumento do vício entre esses indivíduos.

No Brasil, como inexiste tal previsão legal de falências de pessoas naturais (exceção feita ao caso de empresários individuais, hipótese essa irrelevante para o tema sob discussão neste artigo), essa variável que compõe o custo de "perder tudo" seria bastante relevante para jogadores.

Ao analisar esses pontos, alguns autores argumentam que, dado o elevado número de pessoas que têm algum tipo de contato com jogos de azar, é bem provável que a parcela de pessoas que "quebram" em função do jogo seja pequena (na realidade, este seria um subgrupo dentro de um grupo especial, de jogadores patológicos). Outros autores afirmam que a prática autodestrutiva de poucos não deve obstar o exercício de uma prática de muitos (uma situação em que se proíbe dirigir carros porque há pessoas que morrem em acidentes). Em outras palavras, o número excessivo de jogadores não deve levar à proibição de uma prática que, de acordo com muitos autores, é benéfica para uma grande parcela de indivíduos que não comete 
excessos. Certamente, essa linha de raciocínio falha em não enxergar a possibilidade de elaborarmos diferentes estratégias regulatórias para diferentes tipos de usuários uma vez que não estamos restritos a um cenário de one size fits all. ${ }^{15}$

A última categoria de custos, igualmente relevante, engloba os custos associados a aspectos produtivos. Esses custos incluem a perda de salário dos empregados, que faltam ao trabalho devido a problemas relacionados com jogos (tratamento, internação, etc.), e/ou a redução da produtividade. ${ }^{16}$ Alguns economistas argumentam que, tal como as demissões, esses custos seriam privados, uma vez que são arcados pelo empregado ou pelo empregador, não havendo necessariamente um aspecto social neles. No entanto, dependendo do agente econômico que internaliza tais custos, e dos objetivos políticos, pode-se encarar o resultado como negativo e passar a formular respostas regulatórias para endereçar esse "problema”.

Devemos levar em consideração, ainda, os custos burocráticos relacionados a auxílios desemprego, eventualmente pagos para trabalhadores demitidos por causa de problemas com jogos, além dos custos dos próprios auxílios. Ainda que os auxílios propriamente ditos sejam formas de transferências de renda, os custos burocráticos com a administração de tal sistema são eminentemente custos sociais no sentido estrito.

\subsection{BeNEFí́cios}

Continuando nossa análise referente a custo-benefício passaremos a abordar os aspectos potencialmente positivos associados à prática de jogos de azar. Podemos organizar os benefícios a serem aludidos nas seguintes categorias: economia, crimes e utilidade. Como veremos, tal como os custos, muitos dos argumentos comumente apontados como benéficos são mais complexos do que se pode pensar.

A primeira categoria de benefícios já foi amplamente discutida, quando demonstramos como grande parte da discussão é focada no benefício com a legalização da prática de jogos de azar: renda adicional para o governo sem o aumento dos demais tributos. Isto porque, na medida em que uma nova atividade é legalizada - e assim, estimulada, pela redução dos custos associados à ilegalidade -, o governo pode tributá-la, angariando recursos para investir em outras causas como educação, saúde, cultura, esportes. Normalmente aliado a esse raciocínio, há o argumento de que a legalização de jogos pode revitalizar áreas economicamente decadentes, principalmente ao fomentar o turismo. Essas proposições são, no mínimo, complexas e requerem análises mais específicas do que as usualmente disponíveis. Sendo assim, exploremos outros possíveis benefícios associados a jogos de azar.

Assim, a segunda categoria de benefícios se refere justamente à contraparte do primeiro tipo de custo supradiscutido. Trata-se talvez do curioso argumento de que, na realidade, alguns tipos de jogos de azar poderiam ajudar a reduzir a taxa de criminalidade de determinada localidade. Isso poderia ocorrer de algumas formas (GRINOLS e 
MUSTARD, 2006). Primeiro, diretamente, ao aumentar as oportunidades de empregos formais (sobretudo para empregos de baixa qualificação), a indústria de jogos de azar daria uma oportunidade adicional a indivíduos que, caso contrário, optariam por explorar atividades ilícitas como forma de angariar renda; e segundo, indiretamente, devido às externalidades positivas associadas ao aumento no desenvolvimento econômico de certas regiões. Na medida em que determinada região passa por um grau maior de desenvolvimento econômico, crescem sua renda per capita e as oportunidades de emprego em setores legais, dentro e fora da indústria de jogos, com a potencial queda das taxas de criminalidade.

A última categoria de benefício usualmente associada a jogos é, sem dúvida, a mais importante. Ela se resume ao argumento de que os jogos de azar aumentam a utilidade esperada dos jogadores; caso contrário, estes não jogariam. Nessa linha, jogos de azar devem ser equiparados a qualquer outra atividade de lazer. Nesse aspecto, na medida em que jogadores derivam utilidade de jogos de azar, estes podem ser considerados mais um produto de consumo (para lazer) do que de investimento (para ganhar dinheiro). Esse raciocínio é importante, pois serve para outras atividades que geram lazer, mas acarretem riscos. O exercício regulatório, nesse caso, deveria ser permitir o acesso ao lazer, porém, de forma que minimizasse os riscos associados à atividade em questão.

Como já vimos, essa é uma equação difícil que varia em função da atividade. Drogas pesadas, como heroína e crack, podem ser consideradas categoricamente distintas de drogas mais brandas, como cigarros e bebidas alcoólicas. Até alimentos podem ser prejudiciais, tais como os gordurosos. Podemos também pensar em termos de pontos em um espectro, o que realçaria o aspecto gradativo da equação risco-lazer. Aqui, o desafio é definir se a atividade de jogos de azar está mais próxima, por exemplo, do uso de crack ou de comer um Big Mac, este lícito.

Há também uma questão prejudicial. Jogos em cassinos ou outros meios (que não online) envolvem elevados custos operacionais. Devido à necessidade de os ofertantes de jogos de azar cobrirem seus custos (incluindo lucros), eles ofertam apostas não muito vantajosas - com ganho líquido esperado negativo ou muito negativo - para os jogadores. Dado esse cenário, se esperaria que apenas indivíduos amantes do risco derivassem utilidade esperada líquida positiva da prática de jogos de azar. Contudo, se pensarmos que muitos jogadores possuem planos de saúde, casa própria e diferentes formas de seguro, perceberemos como eles demonstram aversão a riscos. Da mesma forma que apenas indivíduos amantes de risco optariam por entrar em apostas com ganho líquido esperado negativo, apenas indivíduos avessos a riscos optariam por comprar seguros, pois os custos cobrados pelas seguradas tornam o ganho esperado com o seguro negativo.

O fato de o indivíduo fazer uma aposta em um jogo de azar com ganho líquido esperado negativo e também comprar uma apólice de seguro pode ser explicado: esse 
indivíduo sobre-estima constantemente a probabilidade de eventos com baixa probabilidade de ocorrer (e.g. ganhos em apostas em jogos de azar e sinistros em apólices de seguro). O jogo ainda seria mais atrativo porque tem custo baixo (ao menos inicialmente), e o retorno pode ser muito alto, mesmo sendo baixa a probabilidade. No caso do seguro, o custo do sinistro é alto e a probabilidade do risco, baixa, o que indica maior racionalidade no comportamento do indivíduo que contrata um seguro.

De qualquer forma, a grande maioria das pessoas não tem experiências passadas significativas ou reiteradas com eventos probabilísticos raros. Em um cenário de incerteza, para que indivíduos tenham a pretensão de tomar decisões cujos resultados maximizem suas preferências, eles precisariam ter capacidade de avaliar corretamente não apenas as consequências associadas a cada alternativa da decisão, mas também as suas probabilidades de ganho.

\section{Alternativas regulatórias: trazendo novos elementos À mesa}

Nesta sessão apontaremos os elementos que estão fora do debate sobre regulação de jogos de azar, os quais entendemos que são altamente relevantes para se pensar em diferentes linhas regulatórias. Ao colocá-los no centro da pauta, esperamos trazer novas perguntas para o debate e novas propostas regulatórias para o setor.

\section{I Tipos de JOGOS}

Por causa da diversidade, os jogos de azar podem ser classificados em categorias, de acordo com suas estruturas e contextos (ou situações) (MILTONS, 2006 e LABRIE e SHAFFER, 2003). Essa categorização é relevante, pois, dependendo das características de um jogo, podemos vislumbrar problemas, particulares ou intensificados, ligados a ele, para pensar em linhas regulatórias específicas e eficazes.

\section{3. i. i Diferenças estruturais}

As diferenças estruturais são aquelas relativas à forma do jogo per se. Estas incluem aspectos como a frequência do evento ou os intervalos entre o pagamento de prêmios; a proporção de sorte ou habilidade envolvida; o tamanho da aposta; o nível de conhecimento para participar do jogo; a probabilidade de ganho ou de "quase acerto"; o grau de participação do jogador; e a natureza social ou antisocial da atividade.

A noção de frequência está relacionada à velocidade com que os resultados (ganhos ou perdas) são divulgados ao apostador e à velocidade com que prêmios são pagos. Nos jogos considerados como sendo de frequência contínua as apostas são divulgados rapidamente, proporcionando ciclos de apostas mais velozes e oferecendo a possibilidade de o indivíduo fazer apostas repetidas em intervalos pequenos de tempo. Podemos citar como exemplos as máquinas caça-níqueis, o videopôquer e as loterias instantâneas. Nos jogos ditos de frequência descontínua, os resultados são divulgados 
com intervalos maiores (possuem ciclos de apostas mais lentos), dificultando um grande número de apostas em intervalos pequenos de tempo. São exemplos: apostas em competições esportivas e loterias (com exceção das instantâneas).

A importância dessa diferenciação está na percepção de que jogos de frequência contínua podem agravar algumas categorias de custos discutidos anteriormente. Como possuem um ciclo de apostas mais rápido, eles contribuem para o desenvolvimento ou agravamento de patologias em jogadores, quando comparados aos jogos de frequência descontínua.

Em contrapartida, pode-se argumentar que os de frequência contínua também podem maximizar os benefícios de alguns jogos, em especial ao proporcionar maiores níveis de utilidade para seus jogadores. Essa proposição depende, em grande parte, de se verificar qual é a atividade que proporciona (normalmente) o ganho de utilidade para o jogador. Será a divulgação do resultado da aposta ou a mera expectativa? Será que o jogador usufrui do jogo quando sabe que perdeu (ou ganhou) ou nos momentos em que espera o resultado e sonha com um possível (porém improvável) ganho? É também possível que ambos os momentos proporcionem ganhos de utilidade para diferentes jogadores, e essa diferença também deve ser levada em consideração.

Esse exercício é relevante para verificar como diferentes jogos resultam no agravamento de alguns tipos de custos, enquanto maximizam certos benefícios. Bastaria esse tipo de raciocínio, ao pensarmos sobre cada tipo de jogo, para poder identificar com exatidão que custos e benefícios estão sendo atenuados ou maximizados, a fim de intervir de forma a maximizar os resultados líquidos da regulação.

Outro aspecto em que as diferenças estruturais entre os tipos de jogos são importantes se refere à possibilidade de estratégias regulatórias que visem variáveis específicas. Por exemplo, características como a proporção de sorte ou habilidade envolvida e a probabilidade de ganho ou de "quase-acerto" demonstram como medidas regulatórias podem endereçar pontos específicos de diferentes formas para jogos distintos. Podemos pensar no caso de regulações que estabeleçam a permissão de jogos que tenham a probabilidade de ganho igual ou maior do que determinado percentual, ou com intervalos mínimos entre os ciclos de apostas.

Esses exemplos tratam de regulações da atividade, algo que pode ser necessário para se corrigir os efeitos negativos decorrentes de falhas de mercado, como no caso de assimetria de informação entre o ofertante do jogo e o jogador. Isto porque é bastante difícil para o jogador saber qual é a probabilidade exata (ou ao menos aproximada, na maioria dos jogos) que ele tem de ganhar; essa informação poderia influenciar sua decisão de jogar e quanto jogar, especialmente se tal probabilidade for demasiadamente baixa. Da mesma forma, podemos pensar em propostas regulatórias que enderecem o volume da aposta máxima total, ou o mínimo de tempo entre as apostas, em determinados tipos de jogos, em especial tratando-se dos de frequência contínua. Com isso, se esperaria uma redução na probabilidade de o 
jogador, estimulado pelo jogo, apostar cada vez maiores quantias a ponto de falir rapidamente, o que atenuaria os custos associados à essa situação.

\section{I. 2 Diferenças contextuais}

Diferenças contextuais (ou situacionais) dizem respeito às condições e ao ambiente em que o jogo é realizado, mas não ao jogo em si. Podemos ressaltar aspectos como a legalidade do jogo, o local e o tipo de estabelecimento que o oferece, a associação com outros tipos de entretenimento, a disponibilidade ou não de bebidas alcoólicas no local, efeitos de luz, cor e som, etc. Como a anterior, essa categorização é importante para se verificar como tipos diferentes de jogos podem agravar alguns custos e maximizar benefícios, ou vice-versa. Similarmente, diferenças contextuais podem auxiliar a pensar propostas regulatórias voltadas a variáveis reguladas específicas.

Os jogos realizados na ilegalidade, como vimos, tendem a aumentar externalidades negativas associadas ao aumento de outras atividades criminosas (exploração da prostituição, tráfico de drogas, lavagem de dinheiro), agravando os custos decorrentes. Na face oposta, vimos como a ilegalidade pode, curiosamente, aumentar a utilidade marginal dos usuários pelo chamado "fator adrenalina". Por outro lado, a legalidade dos jogos é importante para se verificar alguns dos benefícios econômicos e maximizá-los. Certamente, o poder público só será capaz de cobrar os tributos devidos e demais obrigações legais se ele regularizar e fiscalizar uma indústria. Partindo do pressuposto de jogos legalizados, podemos destacar importantes diferenças contextuais - oferta de outros tipos de entretenimento, como, shows, bebidas alcoólicas, efeitos de luz, cor e som -, que são relevantes para avaliar os níveis de atratividade de diferentes tipos de jogos, algo que influencia aspectos relativos ao comportamento dos jogadores, como patologias.

Além disso, a exploração de outras atividades, além do jogo propriamente dito, também aumenta os possíveis canais de lavagem de dinheiro, influenciando o aumento da prática. Se considerarmos que esses atributos normalmente se enquadram como lazer, eles tenderiam a aumentar a utilidade dos jogadores e, na medida em que isso fosse verificado, eles atrairiam mais jogadores, trazendo um impacto potencialmente positivo na arrecadação estatal e desenvolvimento econômico para a região.

Outra diferença contextual que impacta os custos e os benefícios é o local onde o jogo é ofertado. Quando apontamos que os jogos podem contribuir para o desenvolvimento econômico de uma região, em especial ao fomentar o turismo, mencionamos também que a atratividade turística varia de acordo com a localidade sob análise. A contribuição marginal dessa atividade para o desenvolvimento econômico de áreas isoladas, como o Recôncavo Baiano, seria, a princípio, superior se comparada com regiões com tradição turística, como Rio de Janeiro e São Paulo. Diferenças na localidade também têm relevância dentro de uma mesma cidade: zonas menos atrativas e em decadência em um centro urbano teriam mais a ganhar com a 
instalação de uma indústria de jogos do que centros comerciais e turísticos já estabelecidos (poderíamos citar a zona portuária do Rio de Janeiro vis-à-vis o bairro de Copacabana). Essas escolhas também são relevantes, pois as pesquisas apontam que casas de jogos tendem a prejudicar outros negócios à sua volta, como restaurantes, bares e lojas em geral (NGISC, 1999).

Além disso, casas de jogos instaladas próximas a escolas tenderiam a ser mais frequentadas por adolescentes e jovens, que são mais suscetíveis a desenvolver patologias ligadas aos jogos e a ter mais propensão a praticar crimes contra propriedade para jogar e pagar dívidas, agravando todos os custos decorrentes.

O tipo de estabelecimento é também uma característica contextual relevante. Destacamos como a maioria de nós, quando imagina uma casa de jogos, pensa logo em um grande cassino. Essa indústria, no entanto, tem inúmeros tipos de segmentos. $\mathrm{Na}$ verdade, estabelecimentos de jogos mais comuns são as casas lotéricas e as lojas de conveniência, que ofertam loterias, raspadinhas e slot machines. Como dito, esses estabelecimentos possuem benefícios econômicos negligenciáveis e tendem a ser problemáticos, pois implicam maior probabilidade de abuso e contribuição para o desenvolvimento e agravamento de patologias.

Dado esse contexto, um caso bastante interessante para se analisar em termos de diferenças contextuais se refere aos jogos de azar disponíveis na internet. Um dos argumentos levantados a favor da legalização dos jogos online é, no mínimo, interessante. Como vimos, cassinos ou outros meios (que não online) possuem elevados custos de manutenção, o que proporciona apostas com ganho líquido esperado negativo. Como os jogos online têm custos menores para serem montados e operados, seria possível ofertar jogos com melhores chances para os jogadores. Com melhores chances, o ganho líquido esperado poderia se tornar mais atrativo.

Lembremos, contudo, que os jogos online trazem desafios regulatórios peculiares. Em função de suas características, em especial o anonimato dos usuários e a localização de servidores, torna-se extremamente difícil fiscalizar a observância de uma série de regras (e.g. restringir o acesso a menores de idade); isso pode evitar que os objetivos de determinadas estratégias regulatórias sejam alcançados. Além disso, os governos se preocupam com jogos online em grande parte porque estes ameaçam o recolhimento de receitas tributárias e outras vantagens políticas advindas de jogos de azar. Os ofertantes desse serviço podem montar suas pessoas jurídicas em lugares remotos (e.g. paraísos fiscais) e ofertar jogos para qualquer indivíduo em qualquer local do mundo com acesso à internet. ${ }^{17}$

\subsection{TIPOS DE USUÁRIOS}

Os usuários representam outro elemento de grande importância para se pensar em diferentes linhas regulatórias no setor de jogos de azar. Para isso, elaboramos uma simples classificação: os usuários potenciais e os usuários patológicos (MILTONS, 
2006 e LABRIE e SHAFFER, 2003). Como fizemos anteriormente, categorizar tipos de usuários é relevante para se pensar em linhas regulatórias diferentes para atacar problemas específicos de determinado tipo de usuário, de forma mais eficaz e eficiente, atenuando custos e maximizando benefícios.

\subsection{USUÁRIOS POTENCIAIS}

Nessa categoria está inserido o público em geral, pessoas que podem ou não começar a jogar (com preocupação específica para algumas subcategorias, como crianças e adolescentes). Por definição, esse grupo tende a não agravar as categorias de custos já elencadas. Como não são jogadores propriamente ditos, esses indivíduos tendem, em função do jogo, a: (1) não se envolver em crimes contra a propriedade; (2) não apresentar quadros clínicos problemáticos; (3) não correr riscos de falência pessoal; e (4) não comprometer sua capacidade produtiva. Em geral, o principal interesse regulatório em relação à esse grupo seria protegê-lo e alertá-lo quantos aos possíveis custos associados aos diferentes tipos de jogos, conforme já discutido. Assim, para esse grupo de usuários, algumas estratégias regulatórias se destacam como as preferíveis.

Inicialmente, teríamos a solução clássica de diminuir a assimetria de informação. Determinadas pessoas podem não saber ou subestimar as possíveis consequências negativas acarretadas pelos jogos. Uma política regulatória de conscientização do público atenuaria isso. Destacaríamos a política de prevenção. Essa estratégia é particularmente interessante quando se considera um subgrupo relevante dessa categoria, composta de crianças e adolescentes. Isto porque estes teriam menos discernimento quanto aos possíveis efeitos deletérios dessa prática. Dados confirmam que a probabilidade de as crianças e os adolescentes sofrerem com patologias e problemas associadas a jogos tende a ser maior do que entre adultos. ${ }^{18}$ Do mesmo modo, a prática de jogos de azar entre adolescentes costuma estar associada ao uso de drogas e de álcool, baixas notas na escola, antecedentes familiares (pais com problemas associados a jogos de azar) e atividades ilegais usadas para o financiamento da prática.

Esse ponto pode nos levar a argumentar em prol de uma regulação que responsabilize de forma objetiva os cassinos pelo ingresso de menores de idade em suas dependências. Esta seria uma forma de criar incentivos (maior punição) para que os cassinos tivessem interesse em fiscalizar e implementar de forma mais restrita a proibição do ingresso e permanência de menores em suas dependências. Com isso, se garantiria uma redução nos custos de fiscalização, uma vez que os próprios cassinos teriam custos menores para fazer isso.

Teríamos ainda a estratégia de exigir serviços de sinalização e demais informações sobre os possíveis perigos (e.g. vício) com a prática reiterada de certos tipos de jogos. Esta solução nada mais é do que um exemplo de regulação de informação, uma 
das formas de regulação menos custosa, que visa a redução da assimetria de informação na relação jogador-ofertante do jogo, algo que já discutimos neste artigo.

Por último, podemos visualizar a implementação de restrições à publicidade. Por trás desse tipo de proposta estão duas premissas: (1) o reconhecimento de que os jogadores desconhecem ou desconsideram os riscos, mesmo que sejam alertados; e (2) mesmo que os jogadores considerem os riscos, ainda assim, eles fazem escolhas que não correspondem ao seu melhor interesse (RAGAZZO, 2011a). O objetivo com a exigência de informar jogadores não é apenas alertá-los quanto aos riscos do jogo, mas, principalmente, desestimular a prática excessiva.

\subsubsection{Usuários PATOLÓGICOS}

Há uma categoria de usuários que, sem dúvidas, é a mais problemática. São os usuários patológicos, ou seja, aqueles que desenvolveram o vício, e cuja característica é a ausência de controle do impulso de jogar. Esses indivíduos normalmente não conseguem parar de jogar, apesar dos efeitos negativos experimentados na vida pessoal, familiar e profissional.

Quando discutimos as categorias de custos e benefícios, procuramos nos remeter, sempre que necessário, ao caso de jogadores patológicos e apontamos como estes estão diretamente associados, por exemplo, ao aumento de custos relacionados com crimes, em especial crimes contra a propriedade, para pagar dívidas, jogar ou manter as aparências.

Além da patologia em si, que acarreta custos com tratamento, ela é causa direta de uma série de outros quadros clínicos problemáticos como depressão e diversos distúrbios de personalidade. Some-se a isso o fato de que pacientes tratados tendem a desenvolver e apresentar problemas como o abuso de álcool e substâncias ilícitas. Da mesma forma, essa patologia está ligada a perdas financeiras, que agravam os custos associados à falência pessoal, incluindo os custos suportados pelos jogadores (perda de patrimônio), e potencializam as externalidades negativas associadas (e.g. aumento no custo de crédito e de tratamento).

Quanto à categoria utilidade, vimos que jogadores potenciais, assim como jogadores regulares, inicialmente encaram os jogos de azar como lazer e, portanto, derivam consideráveis ganhos de utilidade. No caso de jogadores patológicos, os jogos deixam de ser única e exclusivamente lazer para se tornar vício. E, como todo vício, o ganho marginal de utilidade decorrente de seu exercício é pequeno. Trata-se mais de necessidade do que de prazer. Do ponto de vista regulatório, o grande problema com esse tipo de usuário é que ele não responde a estímulos meramente informacionais. Não adianta prover informação e acabar com a assimetria, pois ele tende a ignorar sistematicamente os riscos a respeito dos quais ele é alertado. Assim, as alternativas regulatórias que restam deixam de ter um caráter meramente informativo e dependem, em grande parte, de aspectos comportamentais. 
Poderíamos ter linhas de ação governamentais e não governamentais para endereçar soluções para jogadores patológicos. Poderíamos ter regulações “prudenciais," que envolvessem medidas para evitar que o jogo se torne uma patologia. Por exemplo, a regulação poderia exigir que os funcionários das casas de jogos fossem treinados para identificar quando jogadores comecem a apresentar traços comportamentais patológicos; isso ajudaria a identificar o problema antes que ele se instalasse ou se agravasse. Da mesma forma, se poderia pensar em regulações quanto ao limite de consumo de álcool por jogador em um determinado espaço de tempo, restrições em relação ao ambiente (luzes, cores, atrações artísticas, etc.).

Esses fatores podem ser importantes tanto para evitar o agravamento de custos (como a falência do jogador) e as externalidades associadas quanto para maximizar os possíveis benefícios (como a utilidade do jogador).

Adicionalmente, tratando-se de um problema clínico, a solução que surge de imediato gira em torno de tratamentos de saúde. Além do acompanhamento profissional e dos medicamentos necessários, apontaríamos o estabelecimento de linhas de ajuda (e.g. grupos de jogadores anônimos) facilmente acessíveis para indivíduos que já desenvolveram (ou tendem a desenvolver) a patologia, e programas de "desintoxicação" ou isolamento, além de acompanhamento posterior e contínuo para esses indivíduos. ${ }^{19}$

Também se poderia criar medidas para evitar que o indivíduo patológico se engajasse em comportamentos que pudessem agravar os efeitos negativos de sua condição, como falência pessoal, agressão aos familiares e a outros indivíduos, e abuso de substâncias ilícitas. Essas medidas incluiriam, entre outros, restrições materiais aos jogadores, ou seja, medidas de restrições ao crédito e estabelecimento de perdas máximas (para determinados perfis), que contribuiriam para que jogadores não apostassem quantias muito elevadas, e reduziria o número de falências pessoais e as externalidades negativas consequentes destas.

\section{Orientando a regulação: VARiáveis REGUláveis}

As variáveis levantadas e discutidas até aqui podem, e devem, auxiliar a mudar o modo como o debate sobre regulação de jogos de azar é travado. Ao explorar as grandes e importantes diferenças entre os tipos de jogos e usuários, e como eles impactam os problemas e benefícios associados aos últimos, e as possíveis respostas regulatórias, esperamos que a discussão mude do tom: de "proibir ou não jogos" para "como regular que tipos de jogos, que tipos de jogadores, e por quê”. Com o necessário vínculo entre todos os elos. Esse novo cenário apresenta um aumento no nível de desafio diretamente proporcional ao aumento no grau de complexidade. Entretanto, o desafio acompanha importantes saltos de qualidade na formulação e na avaliação de alternativas regulatórias para o setor de jogos, que devem atenuar os custos e maximizar os benefícios para a sociedade. 


\section{I ENTRADA}

A primeira variável diz respeito à entrada no setor, e inclui a exigência de que alguém com a pretensão de ofertar jogos preencha uma série de requisitos para ter autorização legal para poder explorar legalmente a atividade. Além de aspectos de eficiência alocativa ligados à limitação do número do ofertantes na indústria, outro objetivo por trás da regulação dessa variável seria a diminuição de assimetria de informação. O exemplo clássico são as provas de ingresso em carreiras profissionais, como o exame da Ordem dos Advogados. Se os clientes não possuem informações ou capacidade cognitiva necessárias para diferenciar bons e maus advogados, assistiremos ao agravamento de um problema de seleção adversa no setor. Uma regulação de entrada consistente na exigência de ser aprovado em uma prova para exercício da profissão conferiria uma espécie de "selo de qualidade" ao profissional aprovado no exame, reduzindo (mas não eliminando) o problema de assimetria (RAGAZZO, 2011b).

No caso do setor de jogos de azar, a regulação de entrada teria o mesmo objetivo. Com os diversos requisitos estabelecidos e exigidos para a concessão de autorização de funcionamento (em sentido amplo), os consumidores poderiam utilizar a informação de que determinado ofertante de jogos é autorizado ou credenciado e presumir que ele atende exigências mínimas de qualidade. Além disso, a exigência de entrada como credenciamento também pode ter a consequência de reduzir custos de fiscalização e de controle dessa atividade. Uma vez que diversas informações são exigidas para o credenciamento, estas estariam disponíveis aos órgãos fiscalizadores, o que economizaria importantes recursos. ${ }^{20}$

A regulação de entrada no setor de jogos teria também um caráter fomentador. Isso pode parecer contraintuitivo, pois a maioria dos exemplos de regulação de entrada em setor regulado trata de regras restritivas (e.g. não se pode exercer uma atividade ou prestar um serviço a não ser que sejam atendidos requisitos legais). Pensemos em tipos de regulação que facilitem a entrada, caso o potencial ofertante preencha os requisitos. Um exemplo seria a concessão de incentivos fiscais. E outro, não relacionado à indústria de jogos, seria o papel da Agência Nacional de Cinema (Ancine) como fomentadora de produção nacional independente, por meio da concessão de recursos. ${ }^{21}$

A facilitação da entrada de ofertantes dispostos a prestar serviços em localidades com poucas opções de lazer ou com baixo desenvolvimento econômico, é um exemplo de regulação de entrada de caráter fomentador. ${ }^{22}$ Em se tratando de jogos de azar, esse aspecto da variável de entrada torna-se relevante para verificar a categoria de benefícios associada a um nível de desenvolvimento econômico maior na região, em especial por meio do incentivo ao turismo.

\subsection{Regulação Prudencial (Qualidade E/ ou informaÇão)}

Dentre as variáveis que têm objetivo prudencial, a regulação de informação talvez 
seja uma das mais importantes. O principal benefício da regulação de informações é a redução da assimetria de informação entre usuários, potenciais ou habituais, e ofertantes. Ao disponibilizar aos indivíduos informações até então não acessíveis, ou acessíveis a um alto custo, se preservaria o direito de escolha e se permitiria que os próprios indivíduos realizassem as suas análises em relação ao custo e ao benefício. Em se tratando de jogos de azar, isso faz especial sentido. Usuários eventuais podem desconhecer os riscos envolvidos na atividade, em especial o risco de vício. ${ }^{23}$

Outro exemplo de regulação de informação envolve restrições de veiculação de propaganda. Ao restringir que determinada indústria divulgue sua atividade, além de alertar o consumidor sobre os riscos que esta acarreta, na prática, estar-se-ia desestimulando a prática excessiva dessa atividade. Podemos pensar na possibilidade de restrições no setor de jogos de azar, já que há jogadores que não deveriam ser incentivados a jogar (e.g. crianças, adolescentes e jogadores patológicos).

Em diversos casos, contudo, regular a qualidade ou a informação pode não ser suficiente para atingir alguns objetivos regulatórios, em especial quando o objetivo é prudencial. Isso é particularmente relevante em situações em que se possui elementos suficientes para crer que (1) os consumidores sistematicamente desconsideram os riscos sobre os quais eles são alertados; e (2) mesmo que os consumidores considerem os riscos sobre os quais foram alertados, ainda assim eles fazem escolhas que não correspondem a seu melhor interesse. Isso exige que se lance mão de instrumentos mais contundentes, que influenciem mais diretamente o comportamento dos usuários. Este é um aspecto crucial em se tratando de regulação de jogos de azar: ao se reconhecer o caráter viciante do jogo, a mera disponibilização de informações para os consumidores pode revelar-se insuficiente. Dada a presunção de que crianças e adolescentes possuem menor discernimento para avaliar corretamente os potenciais riscos de jogos de azar, é necessário proibir o ingresso deles nesses estabelecimentos. ${ }^{24}$ Entretanto, muito mais pode ser feito. Ao tratar dos usuários patológicos, apresentamos instrumentos regulatórios que endereçam o comportamento dos jogadores.

Neste texto demos exemplos de regulações "prudenciais" em sentido estrito, visando evitar que indivíduos se tornem jogadores patológicos e o jogador já patológico se mantenha nessa situação. Destacamos, por exemplo, a exigência de que os funcionários desses estabelecimentos sejam treinados para identificar, nos jogadores, traços comportamentais típicos de patologia e consumo excessivo de álcool, e o estabelecimento de linhas de ajuda e programas de "desintoxicação" ou isolamento. Mencionamos também medidas com o objetivo de evitar que o indivíduo patológico se engaje em comportamentos que possam agravar em grande medida os efeitos negativos de sua condição, como, por exemplo, restrições de crédito e o estabelecimento de perdas máximas. 


\section{CONCLUSÃo}

A implementação de uma estrutura regulatória para o setor de jogos de azar enfrentará ao menos dois desafios. Um, particular e o outro, mais geral. O desafio particular refere-se à ausência quase completa de previsões regulatórias específicas com objetivo prudencial (salvo algumas poucas referências à obrigação de informar). Conforme destacamos, isso é importante, pois, quando se reconhece o caráter viciante de jogos de azar, constata-se que, em certos casos, regular a qualidade ou a informação pode não ser suficiente para evitar que indivíduos se tornem jogadores patológicos, ou que aqueles já viciados se mantenham nessa situação, e adotem comportamentos que lhes são prejudiciais. Isso aponta o desafio de se conceber instrumentos regulatórios específicos visando esses fins.

O outro desafio é mais geral e ubíquo em todos os setores regulados. Trata-se do desafio real e constante de desenhar medidas regulatórias aptas a atingir os objetivos propostos, que minimizem os custos e maximizem os benefícios. Esse desafio tem dois aspectos, um deles é a incorporação de um modelo mais realista sobre o comportamento dos indivíduos, e o outro é o estabelecimento de uma cultura de experimentalismo e uma avaliação regulatória persistente e contínua.

O segundo aspecto desse desafio se sobrepõe, de certo modo, ao anterior. Ele parte da premissa de que o atual sistema para formulação e avaliação de desenhos regulatórios está baseado mais em fé do que em evidências. A real eficácia de muitas regras nunca é avaliada após a sua entrada em vigor. Sem dúvida, como argumentamos neste artigo, uma criteriosa avaliação de custos e benefícios ex ante é necessária e bemvinda. Contudo, isso é apenas metade do caminho. Essa é a etapa em que sabemos menos sobre os efeitos de uma regulação e, portanto, nos baseamos em muitas premissas não testadas e potencialmente controversas. Como resultado, invariavelmente, se dá tiros no escuro em muitas situações, ainda que se tenha a precaução de incorporar evidências de outros países e experiências passadas. Isto não supre a exigência de uma avaliação contínua, o que é alcançado por meio da promoção de uma cultura de experimentalismo e avaliação regulatória ex post (GREENSTONE, 2009). No núcleo desse desafio está a premissa de que não podemos acessar os reais custos e benefícios de uma estrutura regulatória até que ela tenha sido testada na prática.

Como dito na Introdução deste artigo, essa discussão invariavelmente recai sobre importantes decisões políticas. Contudo, esperamos ter trazido à mesa argumentos que possam ser utilizados em debates democráticos racionalmente controláveis. Esse seria um passo no caminho para deixar de tomar decisões importantes fortemente direcionadas por pressões conjunturais e começar a pautá-las pelo resultado de um debate aberto e informado sobre o bem-estar público.

O resultado final não está à mercê dos dados. Quem se arrisca a aumentar a aposta? 


\section{NOTAS}

1 Um recurso às ideias associadas a esse binômio pode ser percebido no Projeto de Lei 442/1991, cujo objetivo é permitir o jogo do bicho. Para nós, o ponto interessante é extraído da justificativa do projeto. Subjacente à proposta está a presunção de que, uma vez legalizando o jogo, se poderá suprimir "sua vinculação, em alguns estados, com o crime organizado", passando a "regulamenta[r] e canaliza[r] seus [do jogo] benefícios para obras de interesse social". Para tanto, ele revoga as provisões do Decreto-Lei n. 3.688 de 1941(Lei das Contravenções Penais), e do Decreto-Lei 6.250 de 1944 que pró́bem a prática.

2 A lógica é similar àquela da indústria do cigarro. Atualmente, o uso e a comercialização de cigarros são permitidos, ainda que com grandes restrições. Contudo, o que vemos é a manutenção de altísimo grau de contrabando e falsificações, com o objetivo principal de fugir dos elevados custos gerados pela pesada regulação e pela tributação nessa indústria. Estima-se que cerca de 35\% do mercado brasileiro seja abastecido por cigarros ilegais (Cavalcante, Tania Maria. O controle do tabagismo no Brasil: avanços e desafios. Revista Psiquiatria Clínica, vol. 32 (5), pp. 283-300, 2005). O mesmo fenômeno também é identificado na indústria de bebidas alcoólicas. Obviamente, não se quer desconsiderar que existem elevados custos associados à manutenção na ilegalidade (e.g. crédito mais caro, impossibilidade de se requerer falência ou recuperação judicial, custo esperado de multas em consequência de diferentes tipos de fiscalização, etc). O ponto é que a legalização também impõe custos aos produtores, que, sendo atores econômicos racionais, realizam uma análise custo/beneficio interna para saber qual é o melhor status para manterem-se. Esse cálculo não é tão simples e a balança pode, algumas vezes, tender para o lado da manutenção na ilegalidade.

3 Esse ponto é destacado nos Projetos de Lei 2.826/2008 e 6.020/2009, que propõem regulamentar a exploração dos jogos de azar em cassinos. A justificativa apresentada ao PL 6.020 de 2009 destaca: "são tantos os municípios onde o movimento turístico poderia ser substancialmente ampliado, caso neles fosse permitida a instalação de cassinos”. Já o PL 2.826 de 2008 expressamente prevê que, na determinação das localidades onde serão estabelecidos os cassinos, devem ser privilegiadas: "as localidades com patrimônio turístico a ser valorizado" ou "as [localidades] com carência de alternativas para o seu desenvolvimento".

4 Analisando cerca de cem comunidades com e sem uma indústria de jogos de azar, o relatório da National Opinion Research Center (Norc) registrou que, em comunidades próximas a cassinos abertos recentemente, as taxas de desemprego, os pagamentos de programas de transferência de renda e de bem-estar e as taxas de seguro desemprego caíram cerca de um sétimo (Norc, 1999, cap. 5). Além disso, o Norc registrou um aumento na renda per capita nas indústrias de construção, hotéis, alojamentos e lazer. Contudo, não registrou aumento na renda per capita total na medida em que os aumentos referidos são compensados por reduções em pagamentos de programas de transferência de renda e bem-estar; além disso, houve uma queda brusca na renda de restaurantes e bares. Resumindo, havia mais empregos nas comunidades depois que os cassinos foram abertos, mas o nível de renda nessas comunidades permaneceu o mesmo, sendo que uma parcela maior da renda vinha de pagamentos de salários e uma parcela menor de pagamentos de programas de transferência de renda e seguro desemprego.

5 Os números são um pouco diferentes, mas convergem em termos de magnitude. Uma pesquisa destacou que em 1996, nos EUA, mais de meio milhão de pessoas estavam empregadas pela indústria legalizada de jogos de azar, ganhando uma renda de quinze bilhões de dólares (Christiansen, E.M. Gambling and the American Economy. In: FREY, James (eds.). Annals of the American Academy of Political and Social Science, p. 556, 1998). Outra afirmou que em 1995 a indústria de cassinos registrou: receitas entre 22 e 25 bilhões de dólares; pagamento de 2,9 bilhões em tributos diretos; 300 mil empregados, pagando 7,3 bilhões em salários; salários médios de 26 mil dólares; investimentos de 3 dólares para cada 1 dólar ganho; 13 empregos diretos para cada milhão de dólares de receita; 400 mil empregos indiretos, pagando 12,5 bilhões em salários (NGISC - National Gambling Impact Study Commission. Final Report. 1999, cap. 7, p. 6, citando outros estudos).

6 Os jogos oferecidos em cassinos variam muito e contemplam, entre outros, jogos de cartas, roleta, blackjack, bacará e máquinas caça-níqueis. Além dos cassinos em terra, existem os cassinos aquáticos. Há basicamente dois tipos de cassinos aquáticos: os riverboat casinos e os docksidecasinos. Os primeiros são operacionalizados dentro de navios, durante cruzeiros ou passeios pelo mar. Por conta dessa característica, a prática dos jogos é limitada pelo período em que é realizado o cruzeiro. Os docksides também são cassinos operacionalizados dentro de navios, mas estes não realizam cruzeiros, ficam ancorados nos portos, o que diminui os custos de operação.

7 O Projeto de Lei 6.405/2009, ao prever a regularização do jogo do bicho, destaca em sua justificativa: "se as leis refletem os anseios da sociedade, a legalização do Jogo do Bicho é medida que se impõe, não só por uma questão 
de tradição - há quase um século que ele existe - como pelo número de brasileiros aficionados dessa modalidade de jogo”. Da mesma forma, o parecer do relator na Comissão de Constituição e Justiça, quando analisando o conteúdo do PL 2.944 de 2004, destacou que o projeto propõe "a legalização do bingo e o bingo de cartela. [...] Com isso, legalizaremos uma atividade já muito comum entre nós”.

8 "In their most rudimentary form, such studies are little more than a crude accounting, bringing together readily available numbers from a variety of disparate sources. [...] The consequence has been a plethora of studies with implicit but untested assumptions underlying the analysis that often are either unacknowledged by those performing the analysis, or likely to be misunderstood by those relying on the results. Not surprisingly, the findings of rudimentary economic impact analyses can be misused by those who are not aware of their limitations" (Norc - National Opinion Research Center). Gambling Impact and Behavior Study: Report to the National Gambling Impact Study Commission. 1999, p. 162. Thompson, W. e Schwer, K. Beyond the Limits of Recreation: Social Costs of Gambling in Southern Nevada. Journal of Public Budgeting, Accounting \& Financial Management, vol. 17 (1), pp. 62-93, 2005. Eles analisaram 99 membros da Associação de Jogadores Anônimos de Las Vegas como uma base para suas estimativas de custo social do jogos. O custo social anual por jogador patológico foi estimado em 19,711 dólares. Contudo, estimativas desse tipo são altamente controversas. Veja Walker, Douglas M. Clarification of the Social Costs of Gambling. Journal of Public Budgeting, Accounting \& Financial Management, vol. 20 (2), pp. 141-152, 2008.

9 Em determinadas localidades, as taxas de criminalidade eram estáveis antes da abertura de cassinos; um pouco menores no primeiro ano de funcionamento, retornavam aos níveis médios anteriores no segundo e terceiro anos de funcionamento do cassino, aumentando depois desse período. No quinto ano do cassino em operação, as taxas de roubo, agressão, furto de automóvel, estupro e homicídio eram, respectivamente, $136 \%, 91 \%, 78 \%, 21 \%$ e $12 \%$ maiores. Estima-se que, depois de cinco anos da abertura do cassino, $8.6 \%$ dos crimes contra propriedade e $12.6 \%$ dos crimes violentos em municípios que têm cassino podem ser atribuídos à existência daquele (Grinols, Earl L. e Mustard, David B. Casinos, Crime and Community Costs, The Review of Economics and Statistics, vol. 88(1), pp. 28-45, 2006).

10 Um estudo registrou que, dos membros do grupo de jogadores anônimos nos EUA, $62 \%$ haviam cometido crimes ou contravenções em razão do jogo; $80 \%$ haviam cometido ofensas civis; e 23\% respondiam por ofensas criminais. Uma pesquisa similar com cerca de 184 membros dos jogadores anônimos mostrou que 56\% admitiram já terem roubado ou furtado para financiar o hábito do jogo. A quantia média roubada ou furtada era de 60 a 700 dólares (com a mediana em 500 dólares) de um total de 11,2 milhões de dólares (Grinols, Earl L. e Mustard, David B. Casinos, Crime and Community Costs, The Review of Economics and Statistics, vol. 88(1), pp. 28-45, 2006, citando outros estudos). Claro, mais uma vez, esses dados estão fortemente sujeitos à controvérsia.

11 Dos identificados como jogadores patológicos, 53,5\% afirmaram que se divorciaram. Compare esse número com 18,2\% de não jogadores e $29,8 \%$ de jogadores de baixo risco. Além disso, mais dos 2 milhões de indivíduos pesquisados identificaram o problema de jogo do parceiro(a) como um fator significante em um divórcio anterior (NGISC, - National Gambling Impact Study Commission. Final Report. 1999, cap. 7, p. 26). Uma pesquisa com quase 400 membros dos Jogadores Anônimos revelou que dois terços já tinham pensado na hipótese de cometer suicídio; $47 \%$ tinham um plano efetivo de cometer suicídio; e 77\% afirmaram que queriam morrer (NGISC, National Gambling Impact Study Commission. Final Report, 1999, cap. 7, p. 25). Uma pesquisa com 500 membros dos Jogadores Anônimos registrou que aqueles tidos como sendo de alto risco para suicídio eram mais propensos a estarem separados ou divorciados (24\%) e terem familiares que jogavam ou eram alcóolatras (60\%). Cerca de $17 \%$ dos jogadores que consideravam o suicídio e $13 \%$ dos que tinham tentado, tinham filhos com algum tipo de vício (NORC - National Opinion Research Center. Gambling Impact and Behavior Study: Report to the National Gambling Impact Study Commission. 1999, p. 160).

12 Parceiros de membros dos Jogadores Anônimos registraram que a maioria sofria de sérios problemas emocionais e havia apelado para bebida, cigarro, excesso de comida e gastos compulsivos. Da mesma forma, parceiros de jogadores patológicos sofriam de enxaquecas severas ou crônicas, problemas intestinais, tontura e dificuldades de respirar, além de problemas emocionais, depressão e isolamento, e sentiam raiva. O grupo de crianças que identificam seus pais como jogadores patológicos era mais propenso a fumar, beber e usar drogas, descrevendo-se como mais infelizes (NORC, - National Opinion Research Center. Gambling Impact and Behavior Study: Report to the National Gambling Impact Study Commission. 1999, p. 159 citando vários estudos).

13 O número de comunidades em Wisconsin que sediavam reuniões dos Jogadores Anônimos cresceu de 6 para 29, 7 anos após a abertura dos primeiros cassinos indígenas em 1992 (Grinols, Earl L. e Mustard, David B. 
Casinos, Crime and Community Costs, The Review of Economics and Statistics, vol. 88(1), pp. 28-45, 2006). O NGISC também registrou em seu relatório um aumento no número de divisões de Jogadores Anônimos, de 650 em 1990 para 1328 em 1998, coincidindo com um período de rápida expansão da legalização do jogo (NGISC, - National Gambling Impact Study Commission. Final Report. 1999, cap 4, p. 17).

14 Quando o jogo é restringido, o custo de consumi-lo aumenta. Por exemplo, em julho de 2000, uma decisão judicial no estado de Carolina do Sul, EUA, baniu as slot machines. Seis meses depois, o número de grupos de Jogadores Anônimos havia caído de 32 para 11, e o número de frequentadores, de 40, em média, para cerca de 1 a 2. Ao longo do mesmo período, o número de chamadas no número de autoajuda que mais recebia ligações no Estado caiu de 200 por mês para zero (Bridwell, Randall e Quinn, Frank L., From Mad Joy to Misfortune: The Merger of Law and Politics In The World of Gambling, Mississippi Law Journal, vol. 72, p. 565, 2002).

15 Ainda que se possa argumentar que uma regulação mais pesada (chegando até à proibição) desse último grupo possa impactar indiretamente a maioria através de apostas menos vantajosas, visto que aumenta os custos dos ofertantes de jogos.

16 Cerca de um quarto a um terço dos jogadores recebendo tratamento nos grupos de Jogadores Anônimos reportou a perda de seus empregos devido a problemas com jogos. Um estudo estimou que mais de $60 \%$ dos indivíduos pesquisados haviam perdido, em média, mais de sete horas de trabalho por mês (NGISC - National Gambling Impact Study Commission. Final Report. 1999, p. 161 citando diversos estudos).

17 No Brasil, o Projeto de Lei 2.429/2007, atualmente em discussão no Congresso Nacional, visa a vedar todos os tipos de jogos de azar realizados pela internet. Na realidade, pode-se argumentar que a atual legislação, que proíbe a exploração de jogos de azar por particulares, já proíbe a exploração e a participação de jogos de azar realizados pela internet, desde que o website esteja hospedado em servidor brasileiro.

18 Cf. Gambling Impact and Behavior Study: Report to the National Gambling Impact Study Commission, p. 100ss.

19 É interessante destacar o argumento de que os cassinos não consideram usuários patológicos como bons clientes; por causa do risco de estes apostarem (e perderem) todo seu patrimônio, os cassinos possuem incentivos para preferir usuários que apostam regularmente uma parcela discricionária de sua renda.

20 Há projetos de lei que regulam a entrada de empresas no setor. Por exemplo, o PL 3.480 de 2008 prevê uma série de exigências para concessão da autorização para exploração do jogo de bingo, incluindo (1) regularidade fiscal; (2) regularidade societária; (3) capital social mínimo de 500 mil reais; (4) regularidade de equipamentos e sistemas operacionais; (5) infraestrutura adequada; (6) contratação regular de empregados; (7) limitação da exploração de um estabelecimento por sociedade empresária, incluindo limitações quanto à estrutura acionária cruzada, dentre outras exigências. Exigências similares são feitas pelos PLs 2.944 de 2004, 2.254 de 2007, e 2.826 de 2008 .

21 O PL 2.826 de 2008 expressamente estabelece que, para determinaros locais onde serão instalados cassinos, devem ser privilegiadas: (1) localidades com patrimônio turístico a ser valorizado; ou (2) localidades com carência de alternativas para o seu desenvolvimento.

22 Também poderíamos pensar em uma regulação com caráter misto (fomentador e restritivo), em que se facilite a entrada de alguns, ao mesmo tempo em que se proíba a de outros.

23 Os PL 2.944 de 2004 e 2.254 de 2007 trazem previsões específicas quanto à necessidade de os exploradores de casas de jogos de azar disponibilizarem alertas aos usuários "sobre a possibilidade de vício em razão de não ser observada a moderação na prática da atividade”.

24 Essa proibição, no entanto, é rara nos PLs em tramitação. Na realidade, encontra-se referência a ela apenas em uma disposição do PL 3.480 de 2008, que proíbe o ingresso de menores de 18 anos em casas de bingo. 


\section{REFERÊNCIAS BIBLIOGRÁFICAS}

BRIDWELL, Randall; QUINN, Frank L. From Mad Joy to Misfortune: The Merger of Law and Politics in the World of Gambling. Mississippi Law Journal, v. 72, p. 565, 2002.

CAVAlCANTE, Tania Maria. O controle do tabagismo no Brasil: avanços e desafios. Revista Psiquiatria Clínica, vol. 32 (5), p. 283-300, 2005.

CHRISTIANSEN, E. M. Gambling and the American Economy. In: James Frey. (Org.) Annals of the American Academy of Political and Social Science, 1998, p. 556.

GREENSTONE, Michael Toward a Culture of Persistent Regulatory Experimentation and Evaluation. In: David Moss; John Cisternino. (Orgs.) New Perspectives on Regulation. Cambridge: The Tobin Project, 2009, p. 111-126. GRINOLS, E. L.; MUSTARD, David B. Casinos, Crime and Community Costs. The Review of Economics and Statistics, v. 88(1), p. 28-45, 2006.

KINDT, John Warren The Economic Impacts of Legalized Gambling Activities. Drake Law Review, v. 43, p. 51, 1994. LABRIE, R.; SHAFFER, H. J. Toward a Science of Gambling Regulation: A Concept Statement. Aga Responsible Gaming. Lecture Series, v. 2, n. 2, 2003.

MILTONS, Michelle M. Regulação dos Jogos de azar na América do Norte: Uma Análise Introdutória. Documento de Trabalho SEAE/MF n. 43, 2006.

NGISC - National Gambling Impact Study Commission. Final Report. 1999.

NORC - National Opinion Research Center. Gambling Impact and Behavior Study: Report to the National Gambling Impact Study Commission. 1999.

RAGAZZO, Carlos Emmanuel Joppert, Regulação jurídica, racionalidade econômica e saneamento básico. Rio de Janeiro: Renovar, 2011a.

O Exame de Ordem (OAB) merece resistir aos ataques? Blog Exame. São Paulo, 2011b. Disponível em:

$<$ http: / / exame.abril.com.br/rede-de-blogs/direito-e-desenvolvimento / 2011 /08/03/o-exame-de-ordem-oab-merece-resistiraos-ataques/>. Acesso em: 10 ago. $2011 \mathrm{~b}$.

THOMPSON, W.; SCHWER, K. Beyond the Limits of Recreation: Social Costs of Gambling in Southern Nevada. Journal of Public Budgeting, Accounting \& Financial Management, v. 17(1), p. 62-93, 2005.

WALKER, Douglas M. Clarification of the Social Costs of Gambling. Journal of Public Budgeting, Accounting \& Financial Management, v. 20(2), p. 141-152, 2008.

WALKER, D. M.; BARNETT, A. H. The Social Costs of Gambling: An Economic Perspective. Journal of Gambling Studies. v. 15(3), 1999.

\footnotetext{
Praia de Botafogo, n. 190 - $13^{\circ}$ andar Rio de Janeiro - 22250-900 Rio de Janeiro - Brasil carlos.ragazzolafgv.br
}

Carlos Emmanuel Joppert Ragazzo

DOUTOR EM DIREITO PELA UERJ Professor AdJunto na FGV DIREITO RIO/CPDE

\footnotetext{
1557 Massachussets Avenue Cambridge - 02138-2995 Massachusetts - USA guribeirolasjd.law. harvard.edu
}

Gustavo Sampaio de Abreu Ribeiro

DOUTORANDO EM DIREITO PELA UNIVERSIDADE DE HARVARD Membro do Centro de Pesquisa em Direito E ECONOMIA, CPDE/FGV DIREITO RIO 
